\title{
Apresentação dos textos
}

\author{
Presentation of texts
}

Julio Cabrera

(Organizador)

Recebido em: janeiro/2015

Aprovado em: fevereiro/2015

Os textos desta coletânea foram escolhidos como se já vivêssemos numa democracia filosófica capaz de albergar os dois métodos, o método-conhecimento e o método-experiência: alguns dos textos são marcadamente acadêmicos, outros de estilo de ensaio mais informal, outros extremamente livres em sua forma de expor idéias e discuti-las. Para o organizador desta coletânea e, creio, para seus participantes, todos esses trabalhos são igualmente filosóficos. Uma das características do métodoexperiência é que ele permite jovens estudantes filosofarem; o método-conhecimento não; antes de poder filosofar segundo esse método, os estudantes terão que ler bibliografias imensas sempre em crescimento, e já serão velhos quando conseguirem. Uma boa parte dos textos deste livro é de autoria de jovens estudantes de filosofia, vários dos quais foram alunos de meus cursos de Filosofia no Brasil e Filosofia em América Latina, ministrados na Universidade de Brasília entre os anos 2006 e 2013, aproximadamente. Competentes em seus estudos regulares, todos eles sentiam fortes desejos de fazer algo "a mais" do que lhes era exigido pelos mecanismos regulares de avaliação ${ }^{1}$. Não apenas queriam estudar pensadores latinoamericanos além dos europeus, senão também experimentar a apresentação de pensamentos através de novos estilos expositivos. Isto poderá ser o obstáculo maior para o leitor deste livro, treinado em certos automatismos de leitura: entrar nos particulares registros em que os diversos textos foram produzidos, que, em muitos casos, fogem das regras habituais do que se considera um trabalho filosófico "bem feito".

Mas a decisão de montar um livro de textos juvenis sobre pensamento latino-americano não foi uma ocorrência sem fundamento, mas algo que decorreu, precisamente, da situação que foi antes descrita, especialmente da atitude de indiferença 
dos estudiosos brasileiros de filosofia a respeito de pensamento latino-americano, mesmo por parte daqueles que se interessam por pensamento brasileiro. Este é o caso de vários grupos brasileiros surgidos nos últimos tempos: o Centro de Filosofia Brasileira, de Rio de Janeiro, em torno do trabalho de Luiz Cerqueira; o grupo FIBRA, Filosofia no Brasil, de Belo Horizonte, liderado por Paulo Margutti; o Grupo de Pensamento e Filosofia no Brasil da UFES, Espírito Santo, com o professor Antonio Vidal Nunes na cabeça; e o grupo de pensamento lusobrasileiro que se reúne anualmente em São João del Rei, e em Portugal. Todos eles estão mais interessados em pensamento de língua portuguesa e ignoram quase por completo o pensamento hispano-americano. Inclusive tenho sentido certa resistência, em minhas conferências pelo Brasil, quando saliento a importância para brasileiros de lerem esses autores, como se o Brasil estivesse decididamente mais interessado em dialogar com Europa, e com o próprio Brasil, mas muito pouco com o resto de América Latina.

Só muito recentemente professores mais experientes começaram a se interessar por alguns aspectos desse pensamento. Em 1997 foi fundado o Instituto de Filosofia da Liberação, que oferece cursos e especializações em pensamento latino-americano, mas com marcado acento posto na filosofia da liberação de Dussel. A figura principal deste grupo é Euclides Mance. Temos também o Núcleo de Estudos em Filosofia Latino-americana, da Paraíba, com o professor Antonio Rufino, a Associação Sul Americana de Filosofia e Teologia Interculturais, com a professora Neusa Vaz e Silva; o Instituto de Estudos Latino-americanos, de Florianópolis, liderado por NildoOuriques, que se ocupa mais com temas de economia e política internacional, e o Núcleo em Estudos em Filosofia Latino-americana, com Daniel Pansarelli. Há alguns estudiosos que conhecem pensamento latino-americano, como o professor Ricardo Vélez Rodríguez, colombiano residente no Brasil, talvez o maior conhecedor de filosofia latino-americana (brasileira e ibero-americana) atualmente no Brasil; também VamirehChacon, de Brasília, e Silviano Santiago, de São Paulo. Fora disso, no plano editorial, existem interesses dispersos pela publicação de alguns clássicos do pensamento latino-americano, tais como Leopoldo Zea, José Ingenieros e José Martí. Poucos filósofos brasileiros sabem o que sejam o Popol Vuh ou o livro

Problemata: R. Intern. Fil. n. especial (2015), p. 48-66 e-ISSN 2236-8612 
de Chilam Balam, como já comprovei muitas vezes em viagens e congressos. Num fino e erudito pensador político como Paulo Arantes, surpreende não encontrar nas mais de 450 páginas de seu livro "O novo tempo do mundo" (2014) qualquer alusão aos autores latino-americanos mais relevantes - Quijano, Kusch, Dussel, Mignolo, Castro-Gómez - ou a eventos de especial impacto latino-americano (a revolução haitiana, a Reforma Universitária de 1918 ou o levantamento zapatista), embora o livro esteja focado no problema das novas temporalidades do mundo, questão crucial para o pensamento latino-americano, como vários ensaios desta coletânea irão mostrar.

A presente publicação é, pois, uma obra órfã, feita por jovens diante da quase total ausência do mundo adulto em um território inexplorado. Seria difícil, quase impossível, montar um volume de textos de filósofos profissionais que mencionassem e estudassem os pensamentos de Matias Aires, Oswald de Andrade, Rodolfo Kusch, pensamento pós-colonial, Aníbal Quijano, Catherine Walsh, Walter Mignolo, o Ariel de José Enrique Rodó ou Frantz Fanon; muitos destes nomes não são sequer conhecidos pelos professores que ensinaram filosofia aos jovens autores desta coletânea. Por outro lado, mesmo nos grupos de professores experientes que começam a se interessar por filosofia da liberação, ainda se conservam as estruturas tradicionais de exposição de idéias, como se o pensamento de Dussel estivesse entrando no risco de transformar-se em mais uma matéria de estudos ao lado de outras. (O propósito há pouco manifesto de traduzir ao português a obra completa de Dussel já começa a mostrar esse tipo de atitude). Aqui talvez os jovens sejam mais capazes de driblar este perigo, sentindo os temas da emancipação na própria pele, como necessidades profundas e urgentes, e não apenas como novos temas de intermináveis considerações e discussões, onde "A idéia de vida em Nietzsche" e "A noção de conatus em Spinoza" se transformem em "O conceito de trans-modernidade em Dussel". Esta publicação aposta nessa incipiência, nessa virgindade teórica ávida de transformações efetivas, pelo menos dentro do ambiente acadêmico e em direção à sociedade como um todo.

Este espírito mais práxico e experimental foi largamente cultivado nos grupos e cursos de Filosofia latino-americana de Brasília, criando uma sensibilidade filosófica peculiar, mais crítica a respeito da própria forma expositiva deste filosofar 
desde América Latina. Mas a pesar desta aposta em favor do autoral e da filosofia-experiência, os colaboradores deste volume não cometem a ingenuidade de regressar aos diletantismos, filoneísmos e adivinhações (para usar alguns dos termos do Paulo Arantes) anteriores à filosofia profissional. Os textos aqui reunidos não tentam fazer mal o que os comentadores e exegetas fazem muito bem, senão que tentam fazer algo diferente. Eu diria que a filosofia apresentada nos textos deste livro responde a quatro características marcantes, que não estão, todas elas, presentes em cada artigo, nem há um artigo que as contenha a todas, mas que todos os artigos distribuem de formas diferentes. Vou chamar estas características: (1) Filosofar insurgente; (2) Filosofar performático; (3) Filosofar antropofágico; (4) Filosofar excluido.

Os textos desta coletânea são insurgentes porque foram escritos contra o que se esperava deles, seja tematicamente, seja estilisticamente. Em primeiro lugar, se esperavam textos de filosofia no único sentido hoje aceito, sobre algum aspecto da filosofia europeia e comentando seus autores; um livro sobre Benjamin, Heidegger, Kant, Platão ou Wittgenstein; não se esperava por textos sobre Oswald de Andrade, Matias Aires e Enrique Dussel. Isto já é uma primeira insurgência, de tipo temático e bibliográfico. Em segundo lugar, se esperava por trabalhos expositivos, com objetivos claros enunciados no início do trabalho, desenvolvimento argumentativo linear onde alguma tese fosse claramente apresentada e comprovada, onde os resultados fossem expostos no final do texto, devidamente documentado em citações - feitas de acordo a regras estritas hilvanadas num fio expositivo sólido. Apesar de alguns dos textos desta coletânea seguirem esses procedimentos, outros estão escritos em estilos fluidos, fragmentários, aforísticos, narrativos, como relatórios, citando poemas, fazendo associações, permitindo figuras literárias e ocorrências intempestivas, desenvolvendo mais de uma linha simultaneamente (algumas das quais nunca se fecham), usando comparações e metáforas, apresentando começos e finais abruptos. Os textos - uns mais que outros - são propositalmente insurgentes em seus estilos; alguns deles apenas in-surgem tematicamente, mas seu estilo é tradicional. A todos eles, uma genuina democracia textual deveria dar acolhida, sem rejeitar

Problemata: R. Intern. Fil. n. especial (2015), p. 48-66 e-ISSN 2236-8612 
alguns como não sendo filosóficos, ou como carecendo de qualidade ou rigor.

Esta insurgência de conteúdos e de estilos não é gratuita nem meramente experimental; ela é fundamentalmente política, no sentido de marcar posição a respeito da história de exclusão que tem caracterizado o pensar desde América Latina, desde a invasão, passando pelas sucessivas imposições fillosóficas: Escolástica, cartesianismo, idealismo, marxismo, positivismo, vitalismo, existencialismo, analítica, pós-modernismo. Insurgência significa recuperar, a través de temáticas e estilos, a nossa própria história filosófica: Resistência à invasão, assimilação crítica da Escolástica aplicando a teologia ao problema indígena, crítica do cartesianismo como racionalismo conquistador, aproximações ao marxismo para pensar a emancipação americana, apropriações do vitalismo e do existencialismo contra um pensamento anti-histórico, recusa a nos auto-descrevermos na diáda modernidade-pós-modernidade. Este histórico insurgente ainda se pauta pelo fio argumental europeu, embora num sentido crítico, mas a través desses posicionamentos, e num sentido mais positivo, a insurgência se da também nas temáticas propriamente americanas que surgem neste novo contexto: as culturas indígenas, com seu rico acervo de categorias para pensar a alteridade e o estar no mundo humano; a religiosidade popular com seus traços característicos e como forma de resistência à modernidade secular e iluminista (enfrentando todas as acusações de "atraso"); a revolução estética que se manifesta em toda América Latina, paralela à revolução epistémica europeia; as filosofias políticas que surgem da realidade das independências formais do século XIX, preparando aos poucos o pensamento da emancipação; as formas de vida que surgem da articulação dependênciaemancipação quando deixamos de pensar-nos dentro da articulação modernidade-pós-modernidade (o que implica não um ignorar o avanço tecnológico ou a globalização, mas a capacidade de gerar uma atitude crítica e apropriadora diante desses fenômenos incontornáveis, sem nunca considerá-los como destinos fatais); e, finalmente, as novas ontologias que surgem da reflexão sobre o estar americano em confronto com as filosofias europeias do ser, levando a novos mapeamentos das formas de ser a partir de experiências da submissão e rebelião em América Latina ${ }^{2}$. É de se esperar que a apresentação destes 
novos conteúdos temáticos afete também as usuais formas e estilos de exposição.

O caráter insurgente da filosofia latino-americana tem um corolário particularmente irritante para os valores vigentes em nossas comunidades filosóficas, e que volta a colocar em discussão as categorias "desde" e "em" América Latina. Em livros sobre pensamento latino-americano costumamos encontrar artigos sobre filosofias pré-colombianas, direitos dos índios, marxismo latino-americano, filosofia da liberação, linguagem e colonização, efeitos políticos dos termos étnicos, a questão da identidade latino-americana, mestiçagem, póscolonialidade, globalização desde América latina e estudos culturais. Por outro lado, encontramos também, nos mesmos livros, artigos sobre a emergência do Positivismo e o Krausismo em América Latina, a recepção da Fenomenologia, o Kantismo e a Filosofia Analítica nos países latino-americanos, assim como estudos de professores latino-americanos sobre filosofia da ciência, epistemologia, ética, lógica e metafísica ${ }^{3}$. Nós temos uma mistura aqui, que é importante apontar. Estes dois grupos de trabalhos assinalam para conceitos divergentes do que seja filosofar desde América Latina. Do ponto de vista aqui assumido - a perspectiva da emancipação e da insurgência contra a dependência - enquanto o primeiro grupo de trabalhos responde a essa preocupação, a segunda representa apenas uma elaboração (que pode ser de "alto nível") de problemáticas européias, que constitui uma contribuição ao conhecimento e desenvolvimento dessas problemáticas nas colônias americanas. Nesse sentido, trata-se de um trabalho que favorece a expansão cultural européia, a menos que esses trabalhos mostrem alguma apropriação latino-americana da fenomenologia, do kantismo, do marxismo ou da filosofia analítica visando uma reflexão sobre dependência e emancipação, algo que está presente, por exemplo, nos trabalhos "Devorando Bergson", de Éder Wen e "Nietzsche no país dos espelhos", de Pedro Argolo, neste volume.

De acordo com os valores vigentes em nossas comunidades, a categoria superior e absoluta é a "qualidade" (entendida, claro, dentro dos padrões estabelecidos). Não interessa aonde aconteça essa qualidade, em quais condições, a serviço de quê ela está e quais as suas conseqüências; só importa que o trabalho seja "excelente", um "bom trabalho de filosofia". 
Também se aposta muito no "interesse" de uma pesquisa filosófica, quando se afirma, por exemplo, que os estudos de Fenomenologia ou sobre Kant também são "interessantes" para latino-americanos. $\mathrm{Na}$ perspectiva aqui assumida, nem o evidente "interesse" de uma questão nem seu tratamento "de qualidade" as legitimam como objetos de pensamento filosófico desde América Latina. $\mathrm{O}$ ser humano tem uma tendência muito forte a se "interessar" pelas coisas, até mostra certa avidez nisso, como forma de fugir do tédio da vida ou do vazio existencial; é relativamente fácil que algo se transforme em objeto de "interesse", sobretudo em nosso mundo consumista. O mero "interesse" que desperta uma questão não pode ser critério para dedicar-lhe atenção e cuidado. Por outro lado, atos eticamente duvidosos e até nefastos podem ser feitos de maneiras tecnicamente excelentes ${ }^{4}$. Desde a perspectiva aqui assumida, a questão crucial nunca pode ser a mera "qualidade" ou "excelência" de um trabalho filosófico, porque poderia tratar-se de um excelente trabalho alienado e sem auto-consciência; a questão crucial é se essa qualidade e excelência estão à serviço da emancipação de culturas, povos e filosofias; trabalhos sensíveis a esta motivação emancipadora primordial poderão, inclusive, não ser tão "excelentes" como os trabalhos internos ao sistema vigente, mas a sua "imperfeição técnica" poderá ser o reflexo de preocupações mais profundas e importantes para a humanidade do que a satisfação de meros "interesses" e curiosidades intelectuais.

Mas - passando agora à segunda característica dos trabalhos aqui reunidos - um filosofar obrigado a ser insurgente não poderá sê-lo apenas programaticamente; ele terá que se insurgir de maneira performática; não a través de discursos meramente referenciais, mas a través de textos que, ao tempo que "falam sobre" conteúdos emancipadores, os praticam e realizam na carne e sangue dos textos mesmos, não prometendoos para o futuro, mas apresentando-os de maneira inadiável no que está sendo lido. Isto leva de volta para a questão das formas e os conteúdos. Um texto com forte conteúdo emancipador mas que conserva os formatos e estilos hegemônicos, não terá se liberado completamente. A liberação tem que acontecer também, e primordialmente, no plano do estilo, no âmbito formal. Isto já foi fortemente sentido por vários dos considerados como grandes pensadores europeus (os casos de 
Hegel, Heidegger e Wittgenstein). Ser e Tempo é uma obra que, apesar de seu conteúdo revolucionário, conserva a forma tradicional do tratado filosófico. Heidegger se deu por conta disso e, em sua obra posterior, oferece textos cuja forma é afetada pelos conteúdos tratados naquela primeira obra, trabalhos que já não se deixam ler da maneira tradicional. Algo parecido acontece entre a Enciclopedia e a Ciência da Lógica, e, em menor medida, entre o Tractatus e as Investigações Filosóficas; em todos esses casos, é a revolução formal o que consuma a revolução temática. Se vivêssemos numa sociedade onde a filosofia-experiência fosse aceita, em lugar de ficar repetindo interminavelmente as teses de Hegel, Heidegger e Wittgenstein, teríamos que nos apropriarmos da atitude com a qual esses grandes filósofos europeus construíram seus pensamentos $5^{5}$. Os textos desta coletânea tentam - consigam ou não - colocar em harmonia conteúdos emancipadores com formas controversas e estilos ousados de exposição. São textos militantes, não apenas teóricos; performáticos, não meramente expositivos; tentam produzir um efeito além do que afirmam, mostrar em seu próprio corpo textual o que se está querendo dizer a través do que expõem.

Em terceiro lugar, os presentes textos são, em sua maioria, antropofágicos. Ao ministrar meus cursos sobre o assunto, e ao escrever meus livros, não me dei por conta de como os estudantes e ouvintes tinham se sentido impressionados pela idéia da antropofagia de Oswald de Andrade. Ao ler os textos, percebi que a convicção antropofágica perpassa a maioria dos pensamentos expostos, seja qual for a temática ou os autores focados. De maneira que, à diferença do seu caráter insurgente e performático, que teve que ser mostrado, o caráter antropofágico dos textos aparece de forma explícita. Os jovens pensadores brasileiros, conscientizados da situação de dependência cultural em que produzimos nossos trabalhos, viram em Oswald possivelmente a única esperança brasileira de uma insurgência formal, que possa levar a uma re-leitura do acervo europeu num veio crítico e devorador. Mas os autores estiveram plenamente conscientes de que havia antes que devorar ao próprio Oswald, deixando de lado seu próprio europeísmo e elitismo. A idéia da devoração antropofágica está, diria eu, até sobre-exposta no presente livro, inclusive mais do que eu o teria desejado. Nesse 
sentido, meu próprio projeto editorial inicial foi, ele também, devorado.

Final mas não banal ${ }^{6}$ : o filosofar aqui exposto é um filosofar excluído. O que isto significa? Precisamente por serem insurgentes, performáticos e antropófagos, estes textos não serão consumidos da maneira habitual, mas visceralmente rejeitados por todos aqueles que tiverem sido treinados no exercício rotineiro de leitura de temáticas e estilos. Alguns destes textos (ou talvez todos eles) aparecerão ao leitor usual de filosofia (e especialmente ao leitor acadêmico de papers) como "sem fio condutor", "sem suficiente apoio bibliográfico", "sem fundamento", "sem universalidade", "diletantes", "obsoletos" ou "triviais". Ao não encontrar o tipo de texto que, reiteradamente, espera encontrar, esse tipo de leitor se decepcionará, sem mesmo fazer a tentativa de interação que os textos propõem. Aqueles leitores que não tenham já rejeitado rigidamente os textos (no sentido da exclusão rígida antes exposta) por tratarem de temáticas "sem relevância" ou meramente "locais" (sem "universalidade"), os excluirão a través da análise ponderada de propriedades: serão considerados textos sem objetivos claros, sem desenvolvimento linear e argumentativo, sem bibliografia atualizada, sem abordagens de temáticas discutidas no mundo todo, e sem conclusões efetivas.

Aqui tem que ser dito algo absolutamente fundamental: para que os textos desta coletânea tenham atingido o efeito esperado, para que eles sejam realmente insurgentes, performáticos e antropofágicos, todas estas críticas levantadas pelo leitor tradicional devem ser verdadeiras. Se tentássemos mostrar que são falsas, procurando re-colocar os textos dentro dos padrões usuais de excelência, se perderia com isso, precisamente, seu efeito crítico e questionador. Não: de acordo com os valores vigentes, a primeira impressão deve ser realmente que os textos aqui apresentados não têm qualidade nem rigor nos sentidos tradicionais (assim como os sons de uma música dodecafônica devem ser insuportáveis para o ouvinte tradicional), precisamente porque estes textos se esforçam em apresentar pensamentos filosóficos de acordo com uma qualidade e rigor de outra ordem, que dependen diretamente do assumir a filosofia como experiência, e não como mero conhecimento. Assim como Dussel afirma que um revolucionário é, no momento da revolução, um criminoso do 
ponto de vista da ordem vigente, da mesma forma um escritor que escreve desde sua experiência filosófica numa comunidade onde vigora irrestritamente a filosofia-conhecimento, é - num primeiro olhar - um incompetente, um diletante, um autor sem rigor. Tudo aquele que esteja tentando abrir uma nova dimensão da filosofia deverá aparecer para a ordem que desafia como rejeitável e desprezível do ponto de vista dos valores vigentes. Desta forma, textos insurgentes devem - num primeiro olhar ser excluidos pela ordem vigente tradicional. A sua inicial e instintiva exclusão faz parte da sua insurgência. De outra maneira, seria uma insurgência sem nenhum efeito crítico, uma "insurgência adaptada", o que é, no mínimo, uma incongruência. A reação irada do público tradicional faz parte da coisa mesma; se ela não acontecer, o texto terá fracassado. Conta-se, pois, com a exclusão como primeira reação ao trabalho filosófico insurgente, aquele que ousa explorar temáticas indígenas, latinoamericanas e brasileiras, e utilizar estilos fragmentários e inconclusivos.

Neste sentido, o filosofar aqui apresentado é um filosofar "selvagem", não num sentido de caos ou brutalidade, mas no mesmo sentido em que os europeus viam os indígenas de América, atitude já de cedo criticada num célebre ensaio de Michel de Montaigne. Num texto chamado "Acerca da inconstância da alma selvagem", o grande antropólogo brasileiro Eduardo Viveiros de Castro resgata uma intuição do padre Antônio Vieira, acerca de como os indígenas fingiam ser evangelizados, mas quando os padres se descuidavam, voltavam a adorar seus velhos ídolos; eram "inconstantes" a respeito da colonização: só pareciam convertidos, para em seguida voltarem a seus antigos costumes. Esta "inconstância", já desde o século XVI, se constituiu como um poderoso instrumento de resistência e de insurgência contra o dominador europeu, numa arma política que os nossos ancestrais ainda nos oferecem como modelo viável para nossos atuais esforços reflexivos reprimidos. O filosofar selvagem, aquele que admite muitas formas de reflexão e de pensamento, muitas temáticas e muitos estilos, deve, hoje em dia - devido à presença ativa da colonização intelectual, intacta desde o século XVI - permanecer "inconstante" exatamente no sentido indígena: temos que fingir que nos convertemos em competentes técnicos filosofantes para obter as nossas habilitações e poder trabalhar; mas, no menor 
descuido do nosso orientador (ausente num congresso internacional pela segunda vez no mês), escrever nossos melhores textos e engavetá-los por um tempo, porque, certamente, não poderemos publicá-los nos meios oficiais, nem apresentá-los em nossas aulas. Nas atuais universidades eurocentradas, o pensar selvagem é obrigado a ser inconstante. Uma forma de "desobediência filosófica" que poderá funcionar enquanto não seja reduzida ao silêncio.

"Um Fa(r)do Tropical: Colônia, Cultura e Poder", de Pedro Argolo, escrito em estilo ensaio de referências múltiplas, começa com um poema de Chico Buarque e acaba com poemas de Oswald de Andrade. Argolo parte de um trocadilho ("FadoFardo") para desenvolver a sua idéia central: o trópico musical e leve corre o risco de se converter em peso morto. Borges, John Malkovich, Macunaíma, Heidegger, Bopp e Iracema são algumas das pontas da estrela, na empreitada de descrever, em cores vivas, a lógica da colonização da cultura. As grotescas críticas de Mário de Andrade à falta de rima e ritmo (perfeitamente propositais) da poesia de Oswald prefiguram ironicamente as críticas do professor de filosofia a falta de rima e ritmo de ensaios filosóficos como este de Pedro Argolo. Em toda a segunda metade do texto, a revolução literária do Modernismo é sugerida, na forma de metáfora didática e perversa, como via possível para uma liberação semelhante da estagnada filosofia no Brasil, presa em seu próprio parnasianismo.

Em "Notas marginais para uma Filosofia desde América Latina", Henrique Guimarães decide experimentar um estilo de exposição insólito: o relatório acadêmico de aulas, espécie de cartilha que tenta expor, em poucas palavras, o conteúdo complexo de um curso. Em lugar de afirmações taxativas, o autor opta pelo uso e abuso de interrogações, como forma de traçar um programa de estudos latino-americanos a través de incógnitas mais que de certezas. Henrique tenta desaparecer por trás de uma narrativa fiel aos conteúdos do Curso, mas não consegue: a seleção do que impressionou no momento é inteiramente pessoal (de fato, ele deixa muita coisa importante de lado, mas que, simplesmente, não entrava em sua particular devoração do evento). $\mathrm{O}$ texto proporciona um elaborado roteiro de conhecimentos que os estudantes de filosofia brasileiros deveriam conhecer, desde a antiguidade indígena ainda em curso

Problemata: R. Intern. Fil. n. especial (2015), p. 48-66 e-ISSN 2236-8612 
(os estudantes conhecem Hesíodo, mas não o Popol Vuh) até a imposição da ideologia pós-moderna, passando pelo uso político da Escolástica e a denúncia do cartesianismo conquistador. Depois da leitura deste curioso "relatório", aparentemente "objetivo", fica mais forte do que nunca a impressão de que a história da filosofia configura uma construção política sobre a qual é sempre possível retornar.

Em "Acerca da existência de pensadoras na América Latina e no Brasil", Ana Miriam Wuensch pratica um primoroso exercício de busca - quase de escavação - de mulheres filósofas no Brasil e na América Latina. Uma idéia inicial do texto, da maior relevância, é que o problema do desaparecimento de filósofos latino-americanos nas histórias da filosofia não deve ser equacionado ao problema do desaparecimento de mulheres de qualquer parte do mundo, e que seria falacioso tentar reduzir um ao outro (assim como, às vezes, o problema do racismo brasileiro pretende diluir-se no problema geral da pobreza). Ela faz notar, com toda propriedade, que no "Diário de um filósofo no Brasil" apenas se enfrenta o primeiro problema, não o segundo, e mostra como é essencial não reduzir o problema do sumiço da mulher ao problema geral de desaparecimento de filósofos latino-americanos. Nesse sentido, as pensadoras sofrem uma dupla operação de exclusão, por latino-americanas e por mulheres. Ana Miriam relaciona, na segunda seção de seu trabalho, uma impressionante lista de mulheres pensadoras, que parte da Colônia e se estende pelo século XX, na forma de professoras e acadêmicas de relevância. Apenas podemos temer que a ansiedade por resgatar mulheres de seu duplo desaparecimento nos faça conformar-nos com comentadoras de pensamento europeu, e deixemos de buscar as mulheres pensadoras autorais, como o fazemos quando exploramos universos intelectuais masculinos. Precisamente porque os dois problemas são diferentes e irredutíveis, talvez o achado de comentadoras de filosofia européia amenize o problema do desaparecimento da mulher sem resolver o problema do pensamento autoral de qualquer gênero. $O$ comentarismo feminino não é melhor que o masculino. Mas este texto tem o mérito de mostrar como as estratégias políticas para levar adiante estes dois problemas ao mesmo tempo, com um mínimo de justiça, não são nada óbvios. 
"Estrangeiros em própria Terra" de Rodrigo Costa, tenta mostrar como é socialmente produzido o paradoxo de que os donos originários das terras americanas sejam vistos como "estranhos" por nós, seus descendentes "ocidentalizados" (ocidentalizados, já que nunca plenamente ocidentais; ocidentais por acidente, ou "acidentados", para usar o jogo de palavras do autor); colonizados em nossa própria pele. Os indígenas não são apenas "sem terra", num sentido geográfico, mas sem lugar, sem chão, num sentido ontológico-existencial; o que lhes fora tirado não poderá recuperar-se a través de mera "redistribuição de territórios" enquanto os indígenas continuem sendo considerados obstáculos para o progresso dentro do tempo da colonialidade. Rodrigo tenta mostrar que a exclusão indígena é mais radical que qualquer outra exclusão, encravada no mais profundo do sistema hegemônico de signos. Não se trata de mera discriminação ou preconceito, mas de algo constitutivo: somos na estrita medida em que o indígena não é. Esta exclusão profunda é provocada, inclusive, também pelos "defensores dos indígenas" (como Bartolomé de Las Casas, e, no Brasil, o padre Vieira). Numa rápida devoração de Heidegger, Rodrigo faz notar a incongruência entre o heleno-centrismo do pensador alemão e a sua esplêndida idéia histórico-existencial do filosofar, que permite pensar a partir de qualquer chão; pois o chão, a diferença do mero solo, é historicamente constituído a través de filosofares concretos, como pode ser o latinoamericano. (Esta concepção de fillosofia faz lembrar a idéia de Farias Brito, da filosofia como "atividade permanente do espírito"). $\mathrm{Na}$ última parte do ensaio, Rodrigo oferece uma vigorosa embora fragmentária incursão pela ontologia araweté, seguindo o convite de Viveiros de Castro, apontando diferenças cruciais entre nosso entendimento ocidental (e acidental) da alteridade, e a maneira como uma tribo indígena brasileira encarava esse mesmo problema, fornecendo riquíssimos elementos inter-culturais. O texto acaba abruptamente, como deveria sempre acabar um texto filosófico: quando o pensador já disse tudo o que tinha a dizer.

"A Utopia Antropofágica", de David Almeida, é um texto escrito em estilo de leitura crítica, de um autor geralmente não considerado filósofo - Oswald de Andrade -, texto introdutório sobre dois escritos deste autor - Marcha das Utopias e Crise da Filosofia Messiânica - onde aparecem elementos teóricos para

Problemata: R. Intern. Fil. n. especial (2015), p. 48-66 e-ISSN 2236-8612 
tentar pensar numa nova forma de fazer filosofia no Brasil. David mostra como esta tentativa de Oswald parte de uma curiosa e original filosofia da história (demasiado original para ser aceita num concurso): assim como para Hegel toda a história do pensamento não passa de tentativas da realização do espírito, e para Heidegger de diversas maneiras de esquecer o ser, segundo Oswald de Andrade toda a história do pensamento não passa de um conflito entre duas formas primordiais de ver o mundo e o humano: matriarcado e patriarcado, o segundo ligado com pensamento messiânico, o primeiro com cultura antropofágica. $\mathrm{O}$ matriarcado é visto como a situação originária inicial, e a história do mundo, tal como a conhecemos, como o predomínio irrestrito do patriarcado; a utopia luta, talvez de forma inglória, por recuperar o matriarcado original. Mas David não se restringe a expor Oswald tentando resgatá-lo de sua corriqueira desaparição acadêmica; também o corrige e completa em vários pontos (por exemplo, cobrando de Oswald a sua inexplicável omissão da revolução haitiana na marcha das utopias), vinculando o filosofar hegemônico com o messianismo, e o filosofar criativo com antropofagia e matriarcado, tentando ler a revolução caraíba também como revolução filosófica.

"Autenticidade da emancipação entre Heidegger e Rodolfo Kusch", de Luan Strieder fazia parte de um texto mais longo, em cuja primeira parte voltava-se a descrever a situação de colonização cultural já suficientemente exposta em outros textos desta coletânea. $\mathrm{Na}$ segunda parte, o autor expõe o instigante pensamento de Rodolfo Kusch, que não é apenas um grande pensador latino-americano, mas pura e simplesmente um grande pensador, ao lado de Foucault, Agamben ou Rorty, com pensamento próprio e diálogo importantíssimo com o existencialismo europeu, particularmente com Heidegger. Em qualquer país interessado genuinamente em pensamento universal, o pensamento de Rodolfo Kusch seria incluído nos curricula de filosofia (junto com o de Leopoldo Zea, Octavio Paz, Ernani Reichman e Enrique Dussel, entre muitos outros), como uma das mais importantes contribuições ao pensamento mundial (não ao pensamento "universal" entendido meramente como pensamento europeu). O texto ataca algo muito específico: as relações entre emancipação e autenticidade, mostrando como a concepção heideggeriana de autenticidade não pode servir à 
emancipação em sentido americano, por estar atrelada a uma ontologia do ser. Utilizando a distinção ser-estar, inexistente em alemão, Kusch sustenta que a emancipação americana teria que basear-se numa autenticidade do estar. Mas Luan capta um impasse nesta tentativa: a emancipação também seria, inevitavelmente, projeto existencial em sentido heideggeriano, e, portanto, ainda atrelado às ontologias do ser. Em seu agora curto texto, escrito em estilo monográfico linear, Luan tenta sugerir uma solução para este impasse.

"Modernização do pensar como violência: o legado das Missões Francesas da USP e o caso Jean Maugüé", de Gabriel Silveira, é um estudo de caso brasileiro em torno do papel das célebres missões francesas que vieram a São Paulo ensinar os brasileiros a filosofar seriamente, tentando acabar com o diletantismo, a improvisação, os modismos, os filoneísmos e as adivinhações daqueles que pensavam ser filósofos só porque assim o declaravam. Gabriel denuncia a violência institucional deste programa, apresentado como parte de um processo civilizatório filosófico. Um desses emissários culturais europeus, o professor Jean Maugüé - através de um célebre documento intitulado $O$ ensino de filosofia e suas diretrizes teria sustentado uma postura dual, e um tanto incongruente, a respeito dos estudos filosóficos, por um lado incentivando a criatividade, por outro aconselhando a leitura da letra miúda dos clássicos, invariavelmente europeus, e se fechando totalmente a qualquer outro tipo de tradição. O primeiro aspecto foi derrotado pelo segundo com o andar dos tempos. O texto, escrito num estilo algo barroco e insistente (mas não reiterativo), coloca o caso das missões francesas dentro do contexto geral da violência justificada em nome do progresso, tema caro ao pensamento de Benjamin, mas raramente aplicado ao contexto latinoamericano, e especialmente ao caso dos procedimentos educativos universitários, cuja violência parece mais desculpável à luz de aparentes "benefícios culturais" que parecem acima de qualquer suspeita.

"Devorando Bergson: um ensaio antropofágico", de Éder Wen é um texto escrito, em parte, em estilo panfletário (sobre tudo em suas contundentes conclusões), em parte em estilo narrativo humorístico (no experimento bergsoniano da última parte). Arranca da constatação da ausência de pensamento filosófico americanista no Brasil, após ter descrito em

Problemata: R. Intern. Fil. n. especial (2015), p. 48-66 e-ISSN 2236-8612 
panorâmica este pensamento (particularmente interessante no momento de debruçar-se sobre o "Ariel" de Rodó, outra monumental lacuna da cultura filosófica brasileira), para buscar na antropofagia oswaldiana rastos de, talvez, o único pensamento americanista brasileiro desse período, mesmo dentro de suas gritantes limitações, já apontadas em outros textos desta coletânea. A antropofagia é claramente exposta por Éder como seletiva, não exaustiva, em agudo contraste com os métodos "estruturais" em voga, perfeitamente canibais, que procuram a deglutição global do objeto sem deixar restos, atitude típica de fome cultural insaciável. A escolha de Henri Bergson como vítima é perfeitamente apropriada, já que se trata de um metafísico imanente capaz de satisfazer as ânsias metafísicas tupis (as nossas), sem cair nas velhas metafísicas teológicas e transcendentes do passado. Depois de capturá-lo, deixamos de lado seus dedos e orelhas dogmáticas e nos comemos com todo prazer sua cabeça e seu peito existenciais (a imanência da vida intensa, sua magnífica crítica contra a espacialização do tempo). Tudo isto regado a humor, bem longe da impostada seriedade acadêmica. Valeria a pena pesquisar o papel do pensamento bergsoniano na história da filosofia latinoamericana na passagem do XIX para o XX, assim como a utilização acadêmica deste filósofo, e desenhar comparações das que pudéssemos apreender muito sobre estilos filosóficos e abordagens intempestivas.

Em "História da Filosofia e Exclusão de Filosofias: o caso Matias Aires", Rodrigo Costa oferece um exercício concreto de desaparecimento de filosofias latino-americanas, estudando o caso do filósofo luso-brasileiro Matias Aires, tentando entender as condições de seu desaparecimento e da sua eventual reaparição. Ele mostra como as próprias histórias da filosofia são responsáveis por esses progressivos "desaparecimentos" de pensadores, ao proporem uma narrativa filosófica, um plot, de acordo a uma seqüência de idéias organizadas em certa direção; os trabalhos filosóficos que não se inserem nessa narrativa, desaparecem. Desta forma, essas histórias não funcionam apenas como memórias, mas também como dispositivos de esquecimento. Rodrigo mostra como a exclusão de Marias Aires não provém estritamente do conteúdo da sua filosofia, já que ele escreveu sobre questões cultivadas também por europeus (por exemplo, La Rochefoucauld e o próprio Hume). Entretanto, 
Hume é considerado um autor de seu século e Matias não, o que sugere o caráter formal da sua exclusão por parte de quem sequer leu atentamente o que ele escreveu. Seria Matias um pensador "extemporâneo"? Rodrigo aponta que apesar do pensamento do Nietzsche ser apresentado como extemporâneo, ele está perfeitamente inserido dentro da história oficial da filosofia; é Matias Aires o extemporâneo e não Nietzsche; os comentadores de Nietzsche acabaram com a extemporaneidade do filósofo alemão. A proposta do texto - escrito em estilo monográfico - é que as histórias narrativas da filosofia deveriam ser substituídas por geografias da filosofia, onde os pensamentos fossem julgados por si mesmos, em seus próprios méritos e propostas reflexivas, e não pelo pedágio pago às narrativas filosóficas oficiais. Para encontrar filosofias no mundo não precisaríamos de um manual, mas de um mapa.

O estilo do trabalho de Pedro Argolo, "Nietzsche no país dos espelhos. Sobre filósofos e fronteiras", é ao mesmo tempo fluido e tenso; musical embora sem renunciar às tensões da demonstração de um ponto em pauta, que vai sendo melhor definido no fluir do texto, não nas primeiras linhas. O texto começa literariamente, de maneira leve, e vai aos poucos metamorfoseando-se em ensaio, como um monstro que adota vagas formas humanas ao longo da leitura. Embora mantenha um fio (o aproveitamento decolonial de Nietzsche), o faz a través de múltiplas referências (Oswald, Marx, Dussel), dandose o direito de escrever como Derrida num meio onde unicamente a Derrida se lhe dá esse direito. A própria idéia de um filosofar anti-erudito e de frestas ou fronteiras é realizada no corpo do texto, ele mesmo fronteiriço. Um texto polifônico, onde o tema do espelho, mais próximo de Lewis Carroll, serve, em sua ambivalência semântica (mero reflexo ou genuína reflexão), para pensar mais uma vez a complicada situação da filosofia no Brasil. Argolo embarca numa abordagem de Nietzsche abaixo do Equador bem diferente dos usuais tratamentos exegéticos, explorando as idéias nietzscheanas de um filosofar bárbaro e tropical, contra a preferência acadêmica pelas zonas temperadas do pensamento. Nesse sentido, Argolo escreve um texto nietzscheano sem meramente refletir Nietzsche na habitual forma de espelhos enfrentados (uma boa metáfora borgiana dos nossos congressos de filosofia). De certo modo, Argolo deixa que Nietzsche se espelhe em seu próprio texto. 
"Retóricas de descolonização", de Elzahra Osman tenta mostrar, num texto em estilo mais acadêmico, com muitas e variadas referências e seguindo, sobretudo, a literatura descolonial, as linhas de força político-afetivas que constroem o projeto identitário europeu na modernidade-colonialidade a partir da rejeição ocidental aos muçulmanos da Andaluzia, na forma de estratégias retóricas que valem mais pelos seus efeitos do que pelo seu enquadramento no verdadeiro ou no falso. Racismos epistêmicos são veiculados através dessas retóricas, e não há outro meio para enfrentá-los do que outras retóricas; argumentos puramente "lógicos" não irão funcionar, nem mesmo se apropriar do assunto. Linguagens e tradições deixam de ter um conteúdo metafísico estável e passam a ser inventadas e re-inventadas; as identidades são constituídas e desconstituídas, e povos inteiros transformados em algo a ser rejeitado ou mesmo destruído. De todos os modos, em alguns pontos do texto, Elzahra sugere que nem todas as atitudes e posturas estejam no mesmo patamar, sendo possível escolher certas retóricas em detrimento de outras. A parte sobre feminismo islâmico é, talvez, a mais instigante, porque coloca claramente que não apenas as necessidades e sofrimentos são impostos pelo colonizador, mas também os próprios meios de "liberação", que ainda devem ser criticados. Um texto inquietante onde transparecem as dificuldades que surgem na escolha de retóricas, num mundo que podemos ver, com certa melancolia, como um incessante jogo de mútuas exclusões.

\footnotetext{
${ }^{1} J a ́$ tive uma experiência editorial semelhante há alguns anos atrás, na publicação Ética negativa: problemas e discussões (Goiânia, 2009).

${ }^{2}$ Sobre ontologias latino-americanas, cfr. MARQUINEZ ARGOTE (2013) $e$ JUAN CEPEDA (2012).

${ }^{3}$ Cfr.A Companion to Latin-American Philosophy (2010).

${ }^{4} \mathrm{O}$ antigo filme de David Lean, "A ponte sobre o rio Kwai", pode oferecer um bom exemplo de como a categoria de qualidade e excelência nunca podem ser máximas ou absolutas, sem ver-se a serviço de que elas estão. Nesse filme, o coronel Nicholson (interpretado por Alec Guinness), assume a construção de uma ponte tentando mostrar aos japoneses a superioridade da engenharia britânica, e de fato a demonstra; mas esquece totalmente que ele é um prisioneiro de guerra que está construindo uma ponte para o inimigo. Esta pode ser uma bela metáfora da situação dos professores de filosofia latino-americanos, tentando construir filosofias "excelentes" $e$ "de qualidade” dentro da dependência, e totalmente esquecidos dela.
}

Problemata: R. Intern. Fil. n. especial (2015), p. 48-66 e-ISSN 2236-8612 
${ }^{5}$ Cfr. Diário de um filósofo no Brasil, "Melancholia...”, pp. 219-240. (Este texto foi acrescentado na segunda edição).

${ }^{6}$ Proponho aqui esta versão descolonizada do "Last but not least" que nossos professores adoram dizer, com perfeita pronúncia britânica.

Problemata: R. Intern. Fil. n. especial (2015), p. 48-66 e-ISSN 2236-8612 